This item was submitted to Loughborough's Research Repository by the author.

Items in Figshare are protected by copyright, with all rights reserved, unless otherwise indicated.

\title{
Quantification of variation in biological input materials and its effect on clinical outcome and manufacture
}

PLEASE CITE THE PUBLISHED VERSION

PUBLISHER

EPSRC

VERSION

VoR (Version of Record)

LICENCE

CC BY-NC-ND 4.0

\section{REPOSITORY RECORD}

Thurman-Newell, Jamie A., Jon N. Petzing, and David J. Williams. 2019. "Quantification of Variation in Biological Input Materials and Its Effect on Clinical Outcome and Manufacture". figshare. https://hdl.handle.net/2134/13278. 
This item was submitted to Loughborough's Institutional Repository (https://dspace.lboro.ac.uk/) by the author and is made available under the following Creative Commons Licence conditions.

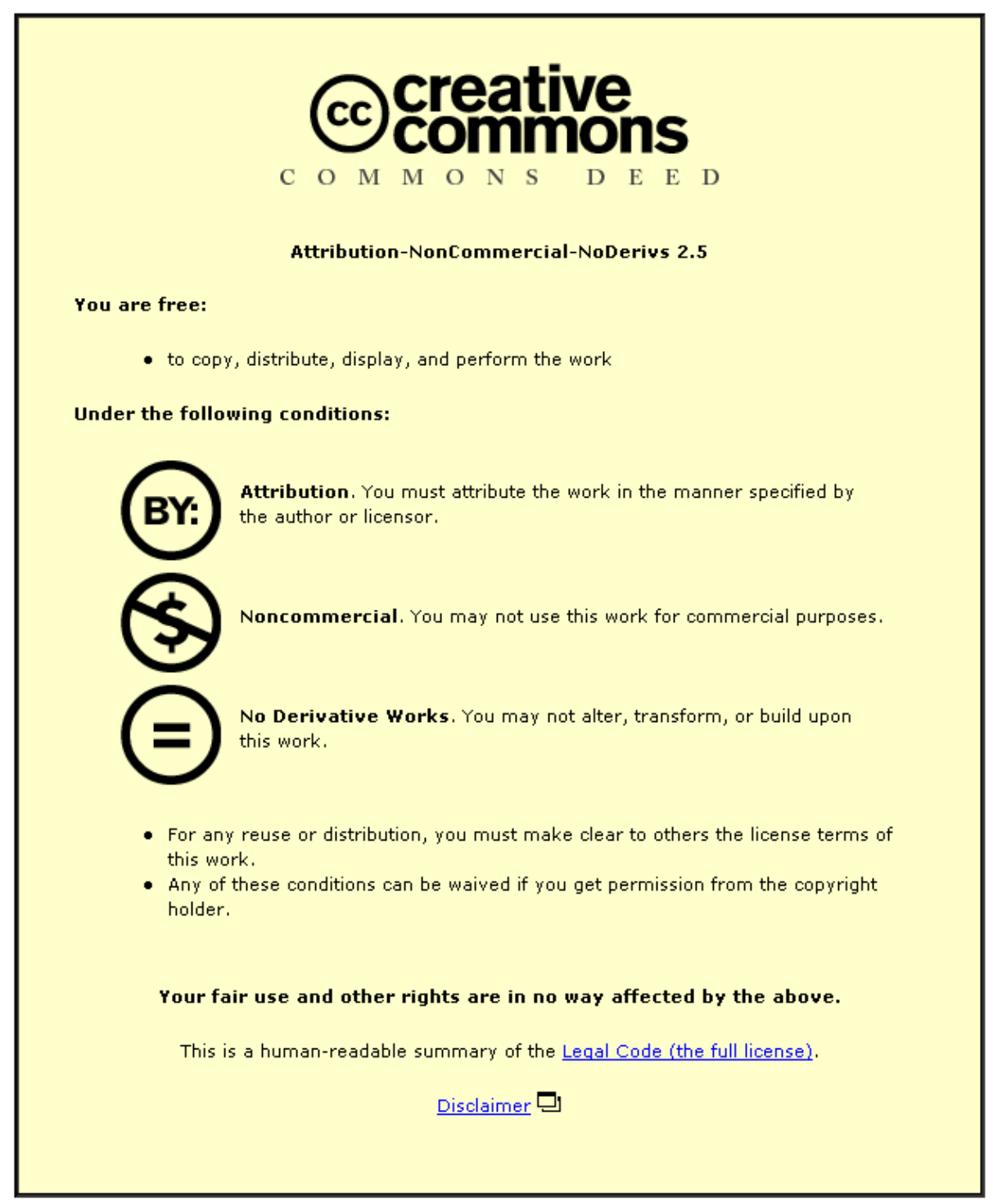

For the full text of this licence, please go to: http://creativecommons.org/licenses/by-nc-nd/2.5/ 


\section{Quantification of Variation in Biological Input Materials and its effect on Clinical Outcome and Manufacture}

Jamie A. Thurman-Newell, Dr Jon Petzing and Professor David J. Williams ${ }^{[a]}$

${ }^{[a]}$ Healthcare Engineering Group, Centre for Biological Engineering, Loughborough University, Holywell Park, Loughborough University, LE11 3TU

\section{Context}

Using blood and blood-based products as a case study, this project will investigate and seek to manage biological input variation from a processing perspective by relating this to clinical outcome (i.e. patient benefit) and exploring the concerns due to input variation when manufacturing a biological therapeutic at multiple sites.

- Hematopoietic stem cell transplants are used to treat blood-based cancer and immunological deficiency

- Over 130,000 transplants were carried out in Europe between 1990 and 2000[1]

- The living cell is the product, introducing more complexity and sensitivity than found in pharmaceuticals

- Humans are the source of the raw material, and we are inherently variable

- Variation affects the cost, the safety of the therapeutic and the efficacy of the treatment

\section{Strategy}

Strategies for dealing with variation will derive from mapping the contributions of each step (see below) in the process and determining their sensitivity. By isolating the greatest sources of variation, the list of difficult problems can be reduced and can inform where time and money should be invested to address this issue. The three stages to this are measuring, explaining and stratifying.

- A systematic search of the literature was carried out for bone marrow \& peripheral blood using PRISMA ${ }^{[2]}$

- This focused on donor characteristics and collected/transplanted cell populations

- A demonstration of the results are shown in Figures 1 to 4

- Each point on the graph represents the median TNC and CD34 positive cell count for an individual study

- 'Error bars' show the range of the recorded cell numbers, and represent the variation

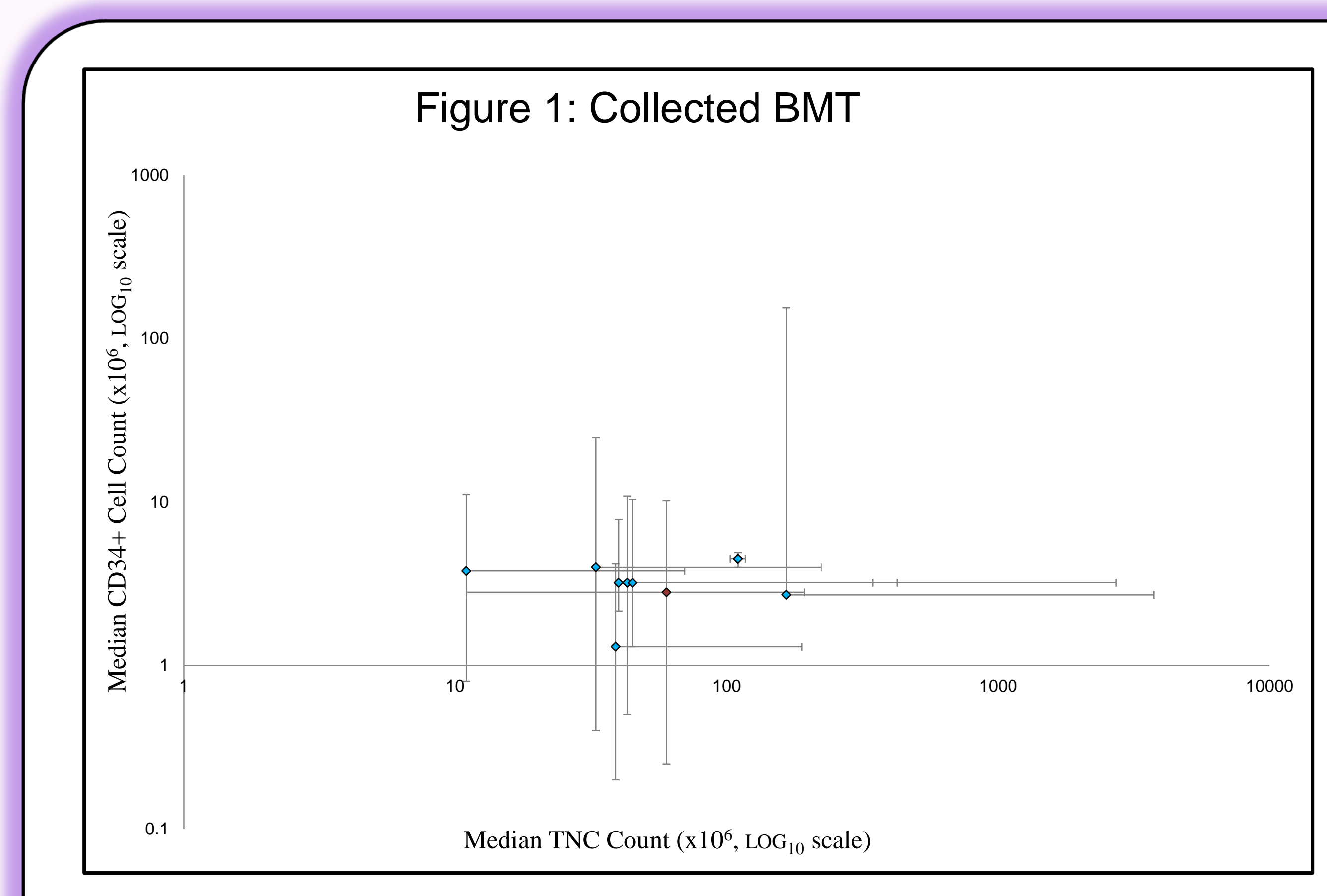

'The biological variation in blood based-products can be up to four orders of magnitude of the median'
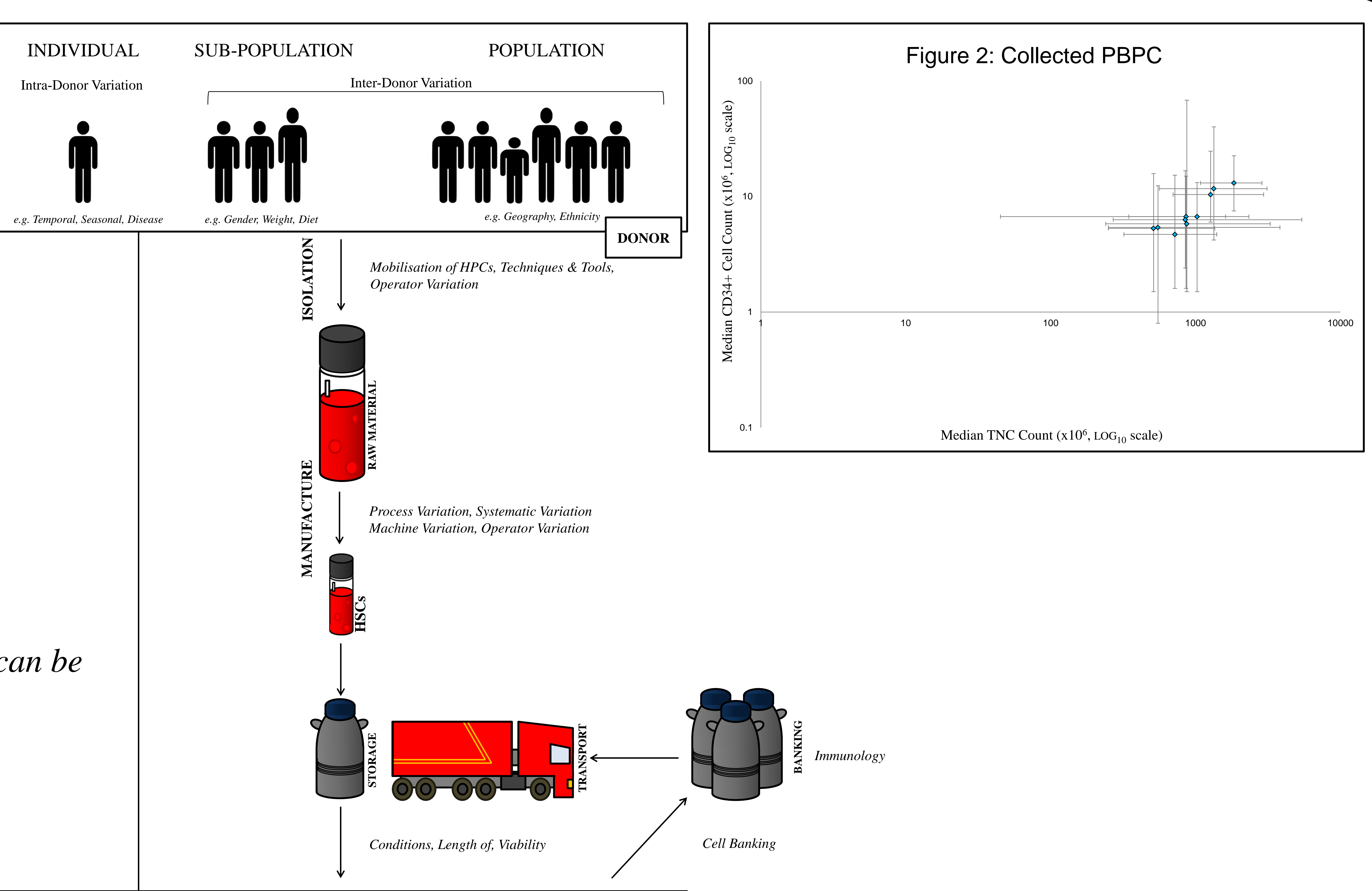

Figure 3: Transplanted BMT
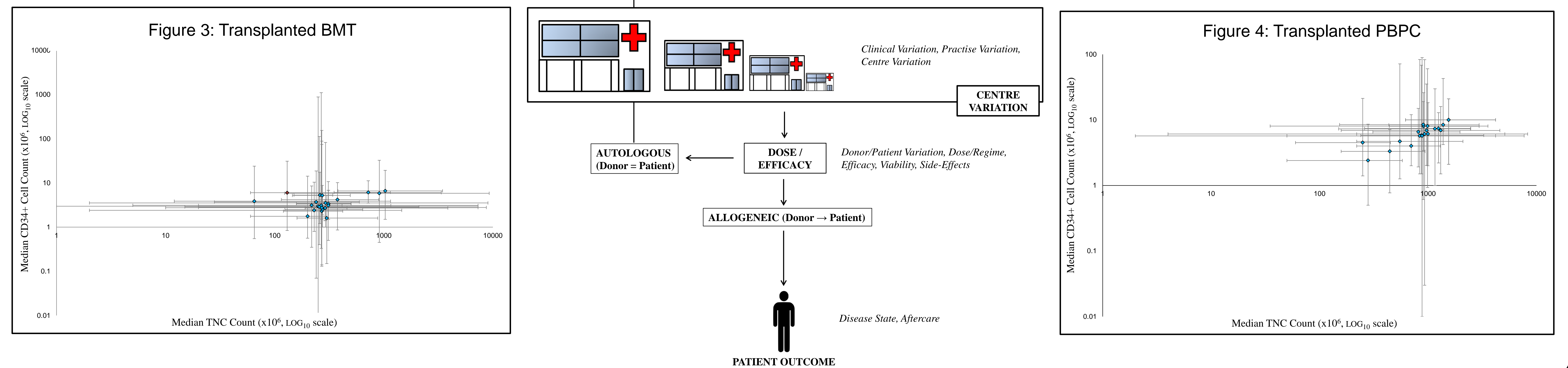

\section{Results}

A critical drawback of this study is that it is based on an incomplete dataset that is limited by the information published in the literature.

- Important donor characteristics such as gender, weight and ethnicity were rarely reported

- Protocols, techniques and equipment were also sporadically reported

- However, Figures 1 to 4 demonstrate the scope of the problem

- The biological variation in blood based products can be up to four orders of magnitude of the median

- The current process may be adding variation up to two orders of magnitude

A more complete dataset is essential to corroborating these findings.

\section{Future Work}

The key outcomes of this project will be strategies for handling complexity in manufacturing and product development consequent from input variation, incorporating measurement precision, for living products.

1. Establish a complete database and applying this database to a therapeutic application (GSK)

2. Map the contributions of input material to clinical outcome (Dana Farber Cancer Institute ${ }^{[4]}$ and GSK)

3. Retrospectively study the trend in biological precision over time to predict the future trend

4. Addressing the issue of measurands (the 'CD34 Issue ${ }^{[3]}$ ) 